Journal of Social and Development Sciences

Vol. 3, No. 1, pp. 6-15, Jan 2012 (ISSN 2221-1152)

\title{
Map Ta Phut as an Exemplar of the Industrial Estates of Thailand
}

\author{
Supaporn Pinyochatchinda, ${ }^{*} J o h n$ Walsh \\ Shinawatra International University, Bangkok Thailand \\ *jcwalsh@siu.ac.th
}

\begin{abstract}
The industrial estate has played an important part in the post-WWII economic development of Thailand, representing a focal point for the inward investment necessary to promote the version of the East Asian Economic Model employed in the country. Industrial estates have also been influential in shaping internal labour migration and in determining which economic activities provide competitive advantage in export sectors. The presence of the estates has not, however, been entirely positive since migration is often associated with social issues, because of excessive industrial pollution and because they made profitable otherwise unprofitable and undesirable activities. One of the largest and most significant industrial estates is that of Map Ta Phut, which is located on the eastern seaboard of Thailand. This estate has become particularly strongly linked with the presence of industrial pollution and with the protests of local residents who claim their health has been negatively affected by the various factories and facilities involved. This paper adopts Map Ta Phut Industrial Estate as an exemplar of all industrial estates of Thailand and uses it to identify the various characteristics and individualities of the Thai version of this institution. By doing this, lessons are drawn for both business practitioners and policy-makers concerning the regulation of pollution and other administrative activities, together with forward planning for employment and labour market upgrading.
\end{abstract}

Keywords: Industrial estate, industrial geography, Map Ta Phut, pollution, Thailand

\section{Introduction}

The spatial location of economic and specifically industrial activities has always been a central part of the Fordist approach to economic development since the 1950s in Thailand that may be labeled a version of the East Asian Economic Model (EAEM) (Walsh, 2010). This has featured import-substituting, export-oriented low labour cost manufacturing, often Original Equipment Manufacturing (OEM) in nature, which was concentrated into certain specific geographical locations. These locations may be configured as industrial estates, industrial parks, business parks, free trade zones, export processing zones and similar structures. In essence, these different configurations all serve the same specific purpose of aggregating industrial activities within a specific location by means of providing incentives to the companies concerned. Doing this has been a specific and central part of the Royal Thai Government (RTG)'s attempt to promote economic development in the Kingdom, as described in the series of five-year plans issued by the National Economic and Social Development Board (NESDB) (Pathamanand, 2009). Industrial estates (IEs), as they are known in Thailand, have come to be administered by the Industrial Estate Authority of Thailand (IEAT). The IEAT has been responsible for co-coordinating the variety of tax incentives and other regulatory benefits together with the provision of physical and, more recently, virtual infrastructure such that estates will appear attractive to potential investors, both domestic and international. IEs have created or at least contributed to a series of problems in addition to the undoubted benefits that they have helped to bring into being. Among these problems, that of pollution in its various guises has become prominent. In this context, the Map Ta Phut IEe has become central in the discourse, often heated, about the nature and location of current and future industrial estates. Developed in 1989, the Map Ta Phut IE mostly houses petrochemical industry facilities. Such facilities represent a constant threat in terms of the release of pollutants into the atmosphere. Map Ta Phut itself is a modern industrial site and one of the largest of its kind in Thailand as a result of deliberate government policy to encourage the economic development of Thailand's eastern seaboard near the city of Rayong (see Figure 1 below). The IE has flourished since the discovery and extraction of hydrocarbons from the Gulf of Thailand and has, subsequently, attracted a number of other investment projects concerned with upstream economic activities. The petrochemicals industry generally in Map Ta Phut is represented at the upstream, intermediate and downstream level of activities. 


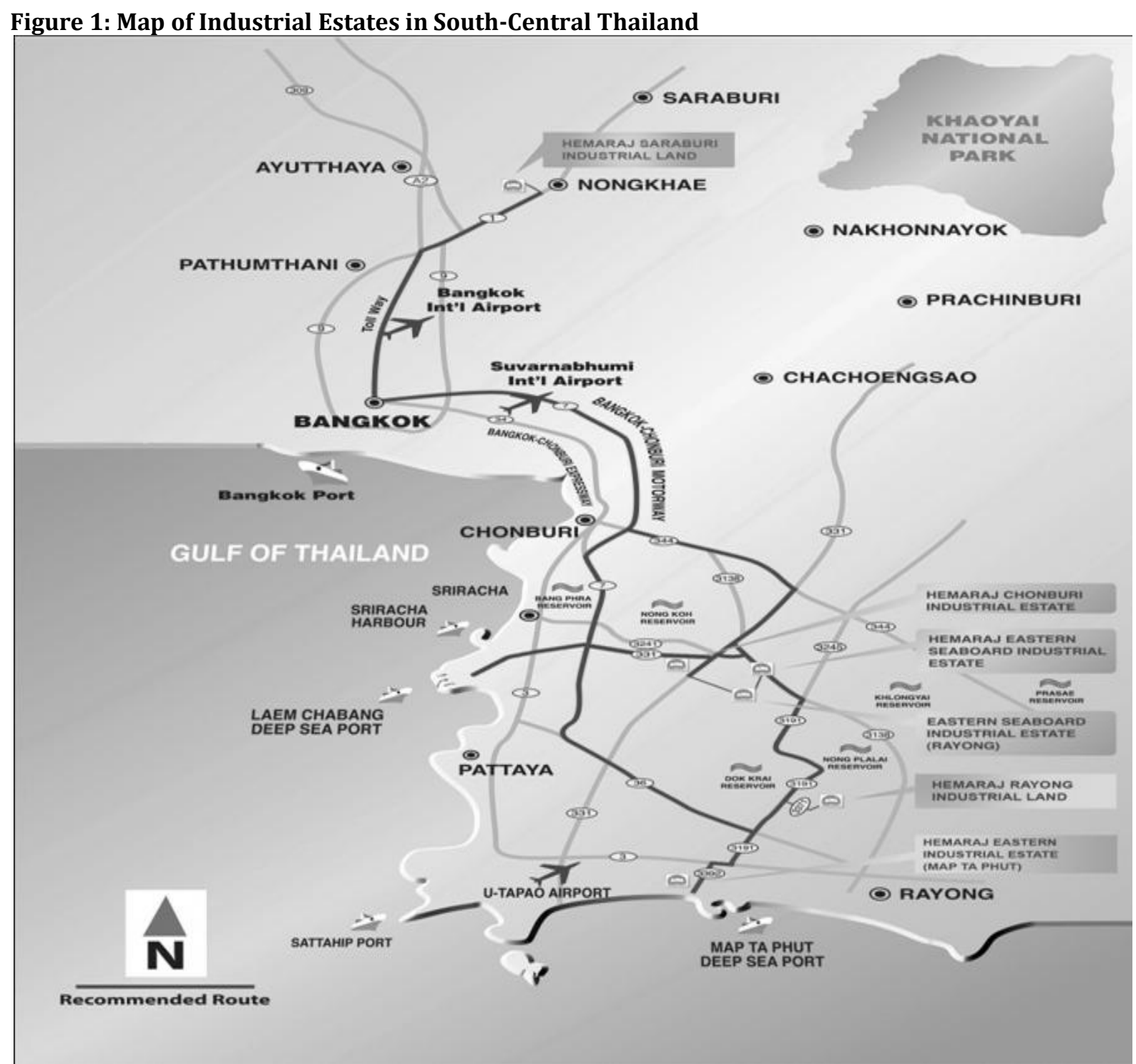

Source: Hemaraj, available at: http://www.hemaraj.com/industrial_eastern_industrial_estate.asp

As a representative of the IEs of Thailand, Map Ta Phut illustrates the commonly seen features of acting as a magnet for internal (and some international) labour migration, the location of contested debates concerning workplace safety and representation and, not least, the presence and threat of industrial pollution both within the estate and for the surrounding vicinity. Is Map Ta Phut, therefore, an exemplar for all IEs of Thailand? In this sense, an 'exemplar' is defined as an example that is worthy of emulation by others in its category. Consequently, the purpose of this paper is to investigate the extent to which Map Ta Phut IE is indeed representative of the IEs of Thailand as a whole and whether the problems that it presents may lead to solutions that will have a wider application across the kingdom. Management at a variety of levels may benefit from the insights that may be gleaned from such an evaluation.

\section{Literature Review}

Industrial Estates: All forms of IE may be incorporated in the concept of the Special Economic Zone (SEZ), which is a specified geographic area in which the normal laws of the land are in some way varied for specific developmental and economic purposes. Perhaps the most well-known examples of SEZ usage is in China when, under the Open Door policy of 1979, a series of SEZs were established on the eastern coast and have 
become the leaders of China's export-oriented industrial growth strategy (Ge, 1999). An IE (or park) is a subset of SEZs and consists of a geographical area in which infrastructure and facilities are provided with a view to encouraging investment there. Investors aim to achieve lower costs by locating in the IE and may also obtain synergies through proximity to other firms, which might have complementary resources or competencies. Some IEs are designated as Free Trade Zones (FTZs) in which goods may be produced without any taxation or duties imposed upon them. Generally, FTZs are aimed at production for export overseas since; otherwise, it would represent a significant increase in competitiveness and possibly unfair competition in the domestic market. An FTZ, then, is usually also an Export Processing Zone (EPZ), which is an IE in which privileges are offered to production of goods for export. Some EPZs will be FTZs but not all, since benefits might include reduced taxation but not zero taxation (Boyenge, 2007). From an economics perspective, the benefits of a geographical clustering of firms dates to the work of Marshall (1890), who argued that traded interdependencies (e.g. in supplier and labour markets) and untraded opportunities (e.g. social interaction and information exchange) act to promote competitiveness. IEs tend to be associated with clusters of industries, which features a "concentration of enterprises producing similar or closely related products in a small area" (Sonobe and Otsuka, 2006).

In addition, some IEs are designated as technology parks or science parks and, in this case, are placed in proximity to universities or other advanced learning institutions. These parks are expected to help produce advanced products through the synergies possible from inter-connections among firms. In the case where a university is involved, a science park might offer opportunities for university faculty to establish their own businesses and might be connected with a business incubator. This approach is perhaps best known in Taiwan's partially successful Hsinchu Science Park (Chen and Choi, 2004). IEs are generally located in sites, which have good transportation links both to sources of important inputs and also to means of exporting. Depending on the type of production, it may be preferable for the location to be close to an airport or a seaport. Map Ta Phut IE, for example, largely deals with bulky industrial products and so is located on the coast where inputs and outputs can be transported most conveniently. In some cases, the IE is located close to a specific resource, which is to be extracted or processed. Irrespective of the location, it is expected as a minimum that the IE provides reliable supplies of electricity and water. For more advanced IEs, reliable highspeed internet connections will also be expected. Many IEs will have their own generating stations in order to guarantee these supplies and will also maintain private security services. This is particularly important for IEs in countries, which have low levels of effective policing and where industrial goods represent valuable items that might be stolen.

IEs may belong to the private or public sector or a partnership of private and public. Public sector IEs are more likely to be aimed at bringing about national developmental goals while private sector IEs are more likely to be aimed at making profits. Of course, there may be a considerable degree of overlap between the two types. For countries with few resources or technical expertise, it may be advantageous for the host government to hire private sector firms from overseas to construct and possibly operate the IE for some period on a turnkey or BOT (build-operate-transfer) basis. The Suzhou Industrial Estate in Southern China, for example, was built with considerable input from Singapore, where spare capital had accumulated and there was a need for additional space and labour, which, according to the theory, could be provided by China (Pereira, 2004). IEs, which attract many factories in labour-intensive sectors, which have been common in Thailand, also need to consider accommodation for those workers. Since IEs tend not to be close to urban areas with widely available spare accommodation, then dormitories must be created for workers and, in some cases, additional family members. Firms will also need to consider providing transportation and catering services. Such IEs tend to act as magnets for labour migration, since the desirability of jobs varies from province to province, depending on the relative wealth of each one. In Thailand, for example, the IE at Lampang has largely drawn workers from the northeastern is a region where incomes are lowest. New jobs can be created by IEs, in other words, that are then taken by out-of-town people (Walsh and Anantarangsi, 2009).

The developmental goals that the state can attempt to promote through the use of IEs include both national and regional levels. At the regional level, a government can create an IE as a means of increasing employment and investment in a depressed area. Japanese manufacturing projects were, for example, encouraged in parts of the UK badly affected by the closure of the mining industry (e.g. Morris, 1988). Such efforts need not just be 
reactive responses to depressed conditions but can b e positive efforts to develop competitive advantages in an area through promoting positive linkages between organizations and between different areas. The opening of bridges and roads better linking Thailand and Laos through the Second and Third cross-Mekong bridges in particular has provided firms in cities such as Khon Kaen with much greater market opportunities in other Mekong region states, particularly in goods which are comparatively low value but bulky and, hence, suitable for road transportation. One effect of the relocation of the Burmese capital from Yangon to Naypyidaw has, among other effects, improved the transportation links between important economic regions in the country and cross-country border points (Preecharushh, 2009). This infrastructure has been built to a considerable extent by Chinese capital, at least partly with a view to improving economic co-operation between Burma and China, not least with respect to piping oil and gas from offshore Burmese fields to Chinese territory. This improvement in infrastructure is exemplified by the development of a new IE project in Dawei (or Tavoy) (Linn, 2010) on the southern coast of the Kra isthmus and the site of a historically important port. It remains to be seen what kind of economic activities will in fact take place there, to what degree genuine competitive advantages are possible and what working conditions are in force for workers in factories in the estate.

IE development has not reached a final point, since states and non-state institutions continue to try to find new ways of refining and improving SEZ projects through improved linkages, training, fostering of new clusters of firms and so forth. The theoretical basis of such developments has been provided by the original work by Porter (1998) and the many attempts to expand upon it. The concept is that successful industrial sectors will emerge in some specific geographical locations if, for various reasons, the important demand and supply conditions are present in or near that area. Hollywood is the obvious example for the film industry. Not only is talent drawn to California because of the presence of studios but also there is access to venture capital and good physical conditions to make films. In some cases, therefore, it should be possible to identify the specific conditions that are required to make a successful industrial cluster and then to create one or else encourage other actors to help to provide it. The state of knowledge of their prospects for economic success concerning IEs from around the world has become such that authorities as august as the World Bank has begun to issue guidelines and lessons from practice (e.g. Zeng, 2010; Farole, 2011).

The ability actually to bring this to pass has yet proved largely elusive, which has given rise to new thinking about how to intensify the value created in specific geographical areas. In Southern China, for example, this attempt is being led by the Guangdong provincial government, which has been moving to create 'specialised towns' which focus on creating a high spatial concentration of firms producing one or a very small number of items (Barbieri, Di Tommaso and Bonnini, 2010), owing to the increased specialization that such actions are known to have produced. In Thailand, a research team led by Porter was commissioned by the government to identify a series of potential clusters that would help to take the economy beyond the factory age of low wage competitiveness in low value added manufactured commodities. This identified areas such as the bioagricultural sector, fashion and parts of what has become known as the knowledge economy. However, the 2006 military coup and subsequent political developments, efforts to create these clusters have largely been abandoned. Instead, the EAEM - low wages, export-oriented, low value-added manufacturing - has been reinstated as the principal means of development. Understanding IEs and their role has, therefore, returned to being a central concern in the effort to make the Thai economy more competitive in an international environment in which China and Vietnam already pose a significant threat to challenge for inward investment, while neighbouring Cambodia has recently entered into its own version of the factory age, with its government agencies enthusiastically pointing to the cheapness of its labour as the means of securing its own improved economic opportunities (Kunmakara, 2010) and shown themselves willing to take whatever actions are required to move inconvenient people out of the way of its developmental infrastructure projects (Crispin, 2007).

Issues Involved with IEs: Although IEs can provide definite developmental goals to states and also promote sustainable competitive advantages for individual firms, there are nevertheless negative impacts associated with the issue, which have been witnessed repeatedly around the world. These include the following:

- Pollution: Concentrations of economic activities in themselves represent a threat to the environment because of elevated usage of resources and the possibility of industrial accidents and spillages. This problem was more intense in the years before the establishment of the polluter pays principle 
(Tobey and Smets, 1996). It is also more intense in the countries where governments have been willing to ignore abuse of environmental regulations for the sake of giving investors an easy ride.

- Market dynamics: providing incentives to firms to invest in a particular IE project by offering financial incentives necessarily makes it possible for otherwise unprofitable activities to become profitable, even though those activities might not be offering any meaningful social benefit. Research in Thailand has indicated that this does take place in at least one IE project (Walsh and Anantarangsi, 2009).

- Labour market abuses: the combination of low wage cost competitiveness, opacity in administration and the desire to please foreign investors has made for a number of instances of abuses of labour in most of the countries in which IE projects have been located (e.g. Mehmet, Mendes and Sinding, 1999; Mason, 2008).

- Social issues: when large numbers of workers gather together in a remote location, whether internal or international, there is scope for various social issues, including family breakdowns, social disorder and enhanced levels of risk-taking activity. Research (e.g. Suocheng et al., 2007) indicates that such activities have been found to be present in IEs. The picture, of course, is complex since many see changes in circumstances as opportunities rather than threats (Michinobu, 2005).

Above all, perhaps, an IE is a geographically-specific space in which industrial activities take place and which acts as a node in an ever-lengthening and deepening network linking spaces with the chain of international capitalism. Such nodes join not just space but people and institutions. As ever, entry into capitalist systems betokens certain changes in the relations between people, institutions and the state. Above all, it brings about Schumpeterian creative destruction in a series of processes that brings winners and losers (Florida, 1996).

What is an Exemplar? An exemplar is an example or model of a particular specimen and one that is worthy of emulation in some way. An IE that acted as an exemplar is one, therefore, which exhibited desirable characteristics in a variety of important criteria. Those criteria would presumably include profitability, good management and the effective spread of capitalism. The purpose of this paper, which is part of a larger research project into the nature of IEs and their use in East Asia, is to determine the extent to which Map Ta Phut IE is an exemplar of all IEs in Thailand and the value of such an investigation lies in the degree to which it can provide a means of evaluating all IEs through the prism of just one. It would also reveal the extent to which it is worthwhile experimenting with different management models in one particular estate with a view to exporting that model to all other estates. For example, there is a clear need to understand the ways in which IEs deal or fail to deal with pollution and whether there exists a management model that can be applied across the Kingdom that would effectively deal with all relevant emissions and their effects on all relevant stakeholders. Consequently, it is the argument and methodology of this analysis to identify the nature and practice of Map Ta Phut IE and to consider it in the context of an exemplary IE. The mode of analysis involved in this effort necessarily includes a subjective component. However, this is unavoidable in the case of a complex set of operations such as the current case in which it is necessary to extract common factors. Purely quantitative analysis would be likely to fail to integrate all the necessary variables with respect to the effort to the difference between the nature and scope of IEs and the circumstances in which they operated. Examining whether Map Ta Phut is an exemplar of the IEs of the Thailand is to consider whether Map Ta Phut represents Thai capitalism accurately and in a way, that further study will reveal insights into the nature of that capitalism. Hence, it is necessary to consider the question of Thai capitalism as a phenomenon in itself.

\section{Methodology}

In this study, the research methodology involved using and integrating mixed types of documents (documentary research) with an approach informed by the concept of analytical induction. A variety of forms of secondary data sources was assembled, including statistics and reports, media stories and academic papers. The research strategy was guided by the desire to obtain diagnostic understanding of the issues: that is, to understand the causal structure of phenomena with respect to industrial estates and their relationships with different stakeholders. This has been conducted as part of a broader doctoral level research project concerning industrial estate environmental management in Thailand. In addition, personal interviewing of a variety of relevant local stakeholders has taken place, often on an informal basis, using semi-structured 
question agendas, which varied in line with the interests and expertise of the stakeholder concerned. Such interviews took place in Thai and involved extensive note taking for subsequent transcription and analysis.

\section{Results}

Thai Capitalism: Although industrialization on a large-scale did not occur in Thailand until the creation of the first five-year plan of the National Economic and Social Development Board (NESDB) in the years following WWII, small-scale capitalism had been present in the Kingdom for many centuries. This rested on the petty trading efforts of internal or cross-border merchants and, later, the monopoly licenses awarded to mostly Chinese capitalists in sectors including tobacco, opium and gambling. From an early part of history, capitalist development was part of a separate and parallel mode of managed economic change kept apart from the majority of the Thai (previously known as Siamese) people. For the majority of commoners, their lives were restricted to rural peasant lifestyles in a hierarchic, slave-owning, feudal society. Slavery was not abolished until 1905 and the class system, although not so restrictive as the Indian caste system, nonetheless had mechanisms in place to hinder social mobility of any sort. Since the creation of the $1{ }^{\text {st }}$ NESDP, Thai economic growth has depended on the entry into the factory age and the promotion of tourism, while also forming a separate class of domestic capitalists capable of their own income-generating activities. The first of these, the factory age, depends on import-substituting, export-oriented low labour cost manufacturing, largely of the OEM form that provides contracted, non-branded goods to international firms who then place their own brands upon them and thereby capture the majority of subsequent profits. IEs were created under the authority of the IEAT, which in turn acted under the supervision of the BOI to ensure that progress towards developmental goals was guided by the hand of the state.

As a modern nation, Thailand has always had a substantial and well-regarded civil service and a predilection (not unique to Thailand of course) for top-down edicts to be enforced by the minor functionaries of the state, which it has been argued was a notable feature of the development of the Eastern Seaboard program as a whole (Doner, 2009). In political debate in the modern age, few if any political parties have argued for a reduction in the size of the state, only the right to determine its actions and to benefit from its largesse, in one way or another. The creation of a new and indigenous group of investor capitalists has had several component parts. Modern business practice in the Kingdom has been driven by overseas multinational corporations (MNCs) and by indigenous business groups that were almost wholly ethnic Chinese in ownership and management (Akira, 1996). Added to this group were new capitalists whose sources of income were directly related to their official position: hence, the numerous generals of the army were given free range to loot the countryside of non-renewable resources such as valuable hardwoods and wildlife species (cf. Mallet, 2000,). The state's role as provider of infrastructure assisted this process by building the roads by which felled trees could be transported while also ignoring the activities taking place. Income generated led to rapid diversification and the creation of complex multi-sector corporations often based on extended family management. It has been rightly pointed out that no Thai corporation of any size has remained in an undiversified state and this is no coincidence.

In terms of the tourism industry, this too has been spatially-determined, with specific areas set aside for capitalist development, notably Pattaya and Phuket as beach and bar locations, Chiang Mai and northern regions for ethnic and adventure tourism and Bangkok as a centre for the marketing, international conference and exhibitions (MICE) market, in addition to urban and cultural tourism. Landowners in critical areas have made a great deal of money and gangsterism has followed those aspects of the tourism industry that yield to extortion or are dominated by cash transactions. In many cases, it has been alleged, zoning regulations have been set aside to permit more convenient exploitation of opportunities, just as the same allegation has been made with respect to the construction of a modern retail sector in the Kingdom.

There are various aspects of Thai capitalism that may be isolated from this analysis. These include the following:

- a heavy and leading role for the state, in different aspects and forms;

- disregard for the physical environment and the confrontation between cultural and folk tradition against capitalist development;

- exploitation of workers as physical inputs which should have costs reduced as much as possible; 
- The determination of specific geographic areas as being places where capitalist development would take place and the preservation of other parts of the state under existing systems of ownership and management.

- Having identified the defining characteristics of Thai capitalism, it becomes clear that an exemplar of that process would also demonstrate the possession of these characteristics. Hence, it is next possible to examine the Map Ta Phut IE in that regard.

Map Ta Phut Industrial Estate: According to the Board of Investment (BOI), there were 58 IEs in Thailand as of October 2010; of these, 42 were under the administration of the Industrial Estate Authority of Thailand (IEAT) and the remainder was either operated by private sector interests independently or as private-public joint ventures (JV). These are divided into three categories: Zones 1, 2 and 3. According to the 2009 IEAT Annual Report (IEAT, 2010), the most recent publicly available, the port area of Map Ta Phut is located on land of 2,870 rai in extent (approximately 1,134 acres or 459 hectares) and the industrial port contains 2 public berths and 7 dedicated berths. The Map Ta Phut Industrial Port Development Master Plan of 2006 divided future plans into three stages: the short term (until 2010), the medium term (2010-2015) and the long term (2015-2020). The first stage of this development was based on the construction of the Inner Basin and its port, which will be addressed by means of a JV approach.

Table 1: Industrial Classification of Facilities at Map Ta Phut Industrial Estate; source: Buakhamsri, 2005: 38-9.

\begin{tabular}{ll}
\hline Category & Number of Companies \\
\hline 1. Oil Refineries. & 2 \\
2. Petrochemicals Industry & 0 \\
2.1. Upstream Petrochemical Industry & 4 \\
2.2 Mid-Stream and Down-Stream Petrochemical Industry & 41 \\
3. Chemical Industry. & 16 \\
4. Chemical Fertilizer Industry. & 1 \\
5. Tire-cord Fabric Industry. & 1 \\
6. Gas (non-Natural Gas) Industries & 8 \\
7. Metals, Iron and Steel Industries. & 11 \\
8. Waste Treatment and Disposals/Landfills & 3 \\
9. Power Generation. & 7 \\
10. Rockwool Insulation & 1 \\
\hline
\end{tabular}

Although the management of Map Ta Phut IE in practice seems to be deficient, there is in fact no lack of official policies or guidelines designed to ensure its efficient administration. Indeed, the public sector has been very active in articulating a regulatory framework and regime under which the area will be both constructed and policed. For example, in terms of the management of safety, vocational health and the environment, the IEAT has established nine operating plans, as follows: 1) Planning, 2) Factory Supervision, 3) Water Quality, 4) Air Quality, 5) Waste Management, 6) Monitoring, 7) Emergency Response Plan, 8) Reporting, and 9) Promoting Industrial Estates and Factories to Meet ISO 14001 in Environmental Management. As has been noted elsewhere, the supervision regime is unsatisfactory in a number of areas. For laws, regulations and policies related to the management of Map Ta Phut IE, there has been a need for the government to upgrade the development of the Eastern Seaboard region such that it can sustain the production of facilities within the categories specified above. The related policies implemented in this context are: 1) Policy to determine investment promotion zone, 2) Local Administration Decentralization Policy, 3) Metropolis and Specified Areas Development Policy, 4) New Economic Zone Development Policy, 5) The Eastern Seaboard Development Program's part which are concerning to Map Ta Phut area, 6) The government policy which affect to Map Ta Phut area, 7) The first phase of the Eastern Seaboard Development Program, (1981-1994), 8) The second phase of the Eastern Seaboard Development Program (1994-present) and 9) Rayong Development Policy.

These policies and plans appear to be extensive and reasonably comprehensive in scope but suffer from a gap in credibility when it comes to comparing the stated situation with reality. Problems emerge in terms of 
resource provision, technical capacity and the turning of institutional blind eyes to problematic areas. Nowhere is this clearer than in the case of environmental management. Map Ta Phut IE has become a byword for environmental pollution in Thailand. One newspaper report provided a summary of the lurid details: "Villagers here avoid walking in the rain because they say it burns their skin and causes their hair to fall out. They have trouble breathing at night when, they say, factories release toxic fumes. And they are terrified by what studies show are unusually high cancer rates (Fuller, 2009)." Pollution is not a very unusual phenomenon in connection with IEs in Thailand. It is best seen as a form of negative externality; i.e. it is a cost passed on by the firm to society as a whole. Since the institution of the Polluter Pays Principle (PPP) in recent years, at least in some developed countries, it has become more possible for civil lawsuits to require polluting companies to face their responsibilities. Consequently, a group of villagers did pursue a legal case against the management of the IE and, in something of a surprise decision; the court upheld their complaint to the extent of closing down the majority of factories operating at Map Ta Phut. This setback for the IE management has been met with some typical hyperbole in the media, who suggest it indicates the end of heavy industry in Thailand and that investors will be likely to switch to the newly-announced facility in Dawei in neighbouring Burma (Myanmar) or, more likely, to China or Vietnam.

This analysis of Map Ta Phut IE has indicated that there has been a strong state element in its creation and maintenance and in the interaction between its actors and the legal system. It is also very evident that a strong location effect is in place when it has come to determining the exact location for the IE, since there is at best only limited scope for moving a port elsewhere and a strong incentive in terms of transportation costs for locating the IE as close to the extracted hydrocarbons as possible. It is also evident that protection of the environment has been set in a subordinate position to the need for maximum revenue generation. This has led to numerous problems with environmental concerns for stakeholders, most notably with respect to neighbouring communities and the health problems they have reported. Notably, a Thai court has sided with the local communities during a period in which Thai capitalist development has been identified with potential damage to the state. Notwithstanding the environmental problems, there is little evidence that workers are being exploited in the Map Ta Phut IE, perhaps because the majority of projects involved comparatively advanced technological processes, which do not lend themselves to the use of low labour, cost competitiveness. It is in this latter area Map Ta Phut is marked out as being somewhat different from the exemplar of all IEs in the Kingdom. It would be necessary, in this case, to distinguish between relatively low and high value-adding activities and related technologies of production.

Discussion: In what senses can an individual industrial estate be an exemplar for all the industrial estates of a country? Various dimensions may be conceptualized and then measured to a certain extent: variability of success based on external activities; production of pollution; place of contention between community, public and private sector interests and location of inward and internal migration, among others. According to these dimensions, the representativeness of Map Ta Phut is evident: pollution and protest have been evident while the configuration of the estates to meet the needs of the export markets served means that all estates will to a certain degree mirror the wider picture. In other ways, Map Ta Phut differs in that its distribution of types of industry does not include the light industry and manufacturing of textiles and electronics that is represented elsewhere. This in turn is likely to have had an impact on the gender distribution of workers and, accordingly, the various social issues that affect or are affected by the presence of migrant workers. A further relevant issue concerns the geographical location of Rayong, which is as mentioned previously on the southeastern seaboard, close to the border with Burma [Myanmar] and not far from the opposite border with Cambodia. Owing to the disparity in terms of economic conditions in Thailand and outside, there are powerful incentives for workers and traders to cross the borders to search for better economic opportunities. This means of course that are many migrants present in the area and these represent options for low cost alternatives for employers willing to drive down employment costs. That situation also exists in other parts of the Kingdom but away from border areas, as a specific destination rather than as a means of swift and temporary crossborder movements. Migrant workers in Thailand from neighbouring countries are subject to a variety of restrictions including the provinces in which they work, the activities they are permitted to undertake and various constraints on living conditions, remittances and so forth. These restrictions do not, naturally, affect the numerous migrant workers who do not abide by the official registration system or who are prevented from doing so by their employers or intermediate agents. 
In border areas where movements are comparatively convenient, more migrants will be present in an unregistered condition and this may have a depressing effect on aggregate wages and, indeed, various health and safety workplace issues, not to mention freedom of association and what limited collective bargaining rights are available. The life cycle issue is one that is also relevant. As the World Bank has pointed out, the Thai economy was able to raise itself from low income to middle income status by application of the East Asian Economic Model but this has led to the Middle Income Trap (Gill and Kharas, 2007) - the means by which the first stage of industrial development has taken place is not the means that will enable the second step to take place. Further, the economy's recovery from the 2008 economic crisis has been based to an inordinate extent to recovering the situation ex ante rather than trying to make some useful plan for the future. Map Ta Phut, with its reliance on heavy industries and processing of chemicals, is vulnerable to the return and repetition of activities with low value-adding capacity. The industries themselves are subject to the claim of membership of the sunset industry category and, hence, their worthwhile lives in current configuration limited. In such a case, there is a need for appropriate government policy and incentives to encourage investors to upgrade their facilities in order to make it possible for additional value to be generated from current investment and some improvements.

Limitations: The most obvious limitation to this research is the limited scope in terms of time and place. Wider ranges in both dimensions would have broadened and deepened the data pool available and hence a more mature and informed analysis would have been possible. Ongoing research aims to rectify this shortcoming at least in part. A second limitation concerns the availability of data from the official sources and the ability to draw additional details from potential respondents. As researchers in Thailand and, indeed, most of Asia will be aware, private and public sector sources are often more opaque about their decisions, statistics and other data than might be desired. Further, there may be disincentives to reveal the truth when it is possible that subsequent government activity might result in law cases. Currently, in the event of pollution disputes and their like, both or all sides to a dispute will sponsor, commission or conduct research in support of the claims that they make. The generally low level of public discourse attendant upon these kinds of disputes, reinforced by the ways in which they are reported in the popular media, means the majority of the population have little indication which form of research is to be trusted, which to be dismissed and why. This research project aims to make a contribution, however modest, to these issues.

\section{Conclusion}

In spatial terms, IEs have been the locations in which the practicalities of industrialized modernization have taken place in Thailand, as they have in various other countries too. One of the principal estates is that of Map Ta Phut, which has become symbolic of the spread of advanced capitalism in the south of Thailand, where land has been transferred from agricultural to export processing purposes, with intensive use of labour and capital replacing the preceding activities. This, in combination with the lax policing schedules, has led to problems with various types of pollution, which were initially swept under the carpet and subsequently contributed to, it is argued, various negative health outcomes. Stakes, opacity and crony capitalism have, it is alleged, increased the problems by firstly denying that they exist and secondly hindering their timely and fair resolution. In this sense, Map Ta Phut Industrial Estate is an exemplar not just of the IEs of Thailand but of the process of economic industrialization as a whole.

\section{References}

Akira, S. (1996). Capital Accumulation in Thailand, 1855-1985, Chiang Mai: Silkworm Books.

Barbieri, E., Marco, R., Tommaso, D. \& Stefano, B. (2011). Industrial Development Policies and Performances in Southern China: Beyond the Specialised Industrial Cluster Program, China Economic Review, in press.

Boyenge, J. P. S. (2007). ILO Database on Export Processing Zones (revised), ILO Working Paper, 251, Geneva: ILO.

Buakhamsri, T. (2005). What is in the air? Secrets that Map Ta Phut and Thai People Have Never Known, Bangkok: Thailand Bucket Brigade.

Chen, S. \& Chong, J. C. (2004). Creating a Knowledge-Based City: the Example of Hsinchu Science Park. Journal of Knowledge Management, 8(5), 73-82. 
Crispin, S. W. (2007). Cambodia's Cowboy Capitalism, Asia Times Online (July 13 ${ }^{\text {th }}$ ), available at: http://www.atimes.com/atimes/Southeast_Asia/IG13Ae01.html.

Doner, R. F. (2009). The Politics of Uneven Development: Thailand's Economic Growth in Comparative Perspective, Cambridge: Cambridge University Press.

Farole, T. (2011). Special Economic Zones in Africa, New York: The World Bank. doi: 10.1596/978-0-82138638-5.

Florida, R. (1996). Regional Creative Destruction: Production Organization, Globalization, and the Economic Transformation of the Midwest. Economic Geography, 72(3), 314-34.

Fuller, T. (2009). In Industrial Thailand, Health and Business Concerns Coincide, The New York Times (December 18 $18^{\text {th }}$, available at: http://www.nytimes.com/2009/12/19/world/asia/19thai.html?_ $\mathrm{r}=3 \&$ th\&emc $=$ th.

Ge, W. (1999). Special Economic Zones and the Opening of the Chinese Economy: Some Lessons for Economic Liberalization. World Development, 27(7), 1267-85.

Gill, I. \& Homi, K. (2007). An East Asian Renaissance: Ideas for Economic Growth, New York: World Bank.

Industrial Estate Authority of Thailand (IEAT). (2009). IEAT Annual Report, 2009, Bangkok: IEAT, available at: http://www.ieat.go.th/IEAT/ieat_docs/annuay/ArIEAT2009\%28E\%29.pdf.

Kunmakara, M. (2010). Cheap Labour Pays Dividends, The Phnom Penh Post (July 9th), available at: http://www.phnompenhpost.com/index.php/2010070940377/Business/cheap-labour-paysdividends.html.

Linn, T. (2010). Dawei Deep-Sea Port, SEZ Gets Green Light, and Myanmar Times (November 15-21st), available at: http://www.mmtimes.com/2010/business/549/biz54901.html.

Mallet, V. (2000). The Trouble with Tigers: The Rise and Fall of Southeast Asia, London: Harper Collins Business.

Marshall, A. (1890). Principles of Economics, London: MacMillan.

Mason, P. (2008). Live Working or Die Fighting: How the Working Class Went Global, London: Vintage Books.

Mehmet, O., Errol, M. \& Robert, S. (1999). Towards a Fair Global Labour Market: Avoiding a New Slave Trade, London and New York: Routledge.

Michinobu, R. (2005). Lives in Transition: The Influence of Northern Thailand's Economic and Cultural Change on Young Factory Women's Sexual Behaviour and HIV Risk, Nakhon Pathom: Centre for Health Policy Studies, Mahidol University.

Morris, J. (1988). The Who, Why and Where of Japanese Manufacturing Investment in the UK, Industrial Relations Journal, 19(1), 31-40.

Pathamanand, U. (2009). The Relationship between the State and Private Sector in Industrial Policy (1960present): from Alliance System to Oligopoly, in Suthiphand Chirathivat and Ng Chee Yuen (eds). Emerging Asia's Growth Practices: Recent Experiences of China, Indonesia, Malaysia, the Philippines and Thailand, Bangkok: Chula Global Network, 380-408.

Pereira, A. (2004). The Suzhou Industrial Park Experiment: the Case of China-Singapore Governmental Collaboration, Journal of Contemporary China, 13(38), 173-93.

Porter, M. E. (1998). Clusters and the New Economics of Competition. Harvard Business Review (NovemberDecember), 77-90.

Preecharushh, D. (2009). Naypyidaw: New Capital of Burma, Bangkok: White Lotus.

Sonobe, T. \& Keijiro, 0. (2006). Cluster-based Industrial Development: An East Asian Model, Basingstoke: Palgrave Macmillan.

Suocheng, D., Li Zehong, L. B. \& Xue, M. (2007). Problems and Strategies of Industrial Transformation of China's Resource-Based Cities. China Resources, Population and Environment, 17(5), 12-17.

Tobey, J. A. \& Henri, S. (1996). The Polluter-Pays Principle in the Context of Agriculture and the Environment. The World Economy, 19(1), 63-87.

Walsh, J. \& Sittichai, A. (2009). Management Style of Chinese Business Owners in the Chiang Rai Province of Thailand, Southeast Asian Journal of Management, 3(1), 29-40.

Walsh, J. (2010). The Rise and Fall of the East Asian Economic Model in Thailand, paper presented at the International Colloquium on Business and Management, Bangkok (January $26^{\text {th }}-28^{\text {th }}$ ).

Zeng, D. Z. (2010). Building Engines for Growth and Competitiveness in China, New York: World Bank, 2010). doi: 10.1596/978-0-8213-8432-9. 